\title{
Analisis Kinerja Aset Pasar Rakyat Kabupaten Bandung Berdasarkan SNI (Studi Kasus Pasar Rakyat Ciwidey)
}

\author{
Asset Performance Analysis of Traditional Market in Bandung \\ Regency Based on SNI (Case Study of Ciwidey Traditional Market)
}

\author{
Nurlaila Fadjarwati $^{1, \mathrm{a})}$, Rima Midiyanti ${ }^{1, \mathrm{~b})}$, Jaka Sastrawan ${ }^{1, \mathrm{c})}$ \& Dewi Wulandari ${ }^{1, \mathrm{~d})}$ \\ ${ }^{1)}$ Program Studi Manajemen Aset, Politeknik Negeri Bandung, Bandung.
}

Koresponden : ${ }^{a}$ nurlaila.fadjarwati@polban.ac.id, ${ }^{b}$ rima.midiyanti@polban.ac.id

c) jaka.sastrawan@polban.ac.id \& ${ }^{d)}$ dewi.wulandari@gmail.com

\begin{abstract}
ABSTRAK
Penelitian ini bertujuan untuk mengetahui kinerja aset Pasar Ciwidey di Kabupaten Bandung. Standar Nasional Indonesia (SNI) 8152:2015 mengenai pasar rakyat digunakan sebagai tolak ukur dalam menggali kesesuaian antara fasilitas yang ada (existing) dengan kondisi standar. Penelitian ini menggunakan metode deskriptif dan didukung dengan data kualitatif untuk mendapatkan sumber informasi yang valid agar dapat menjawab kebutuhan mengenai Pasar Ciwidey. Pengukuran kinerja aset pasar didasarkan pada aspek fisik, penugasan \& peralatan, aspek lingkungan, keselamatan dan kesehatan. Hasil dari penelitian menemukan ketidaksesuaian fasilitas-fasilitas yang digunakan di Pasar Ciwidey dengan SNI 8152:2015 yang digunakan sebagai tolak ukur penelitian. Pasar Ciwidey belum bias memenuhi kesesuaian aset yang dilihat dari aspek fisik, penugasan \& peralatan, aspek lingkungan, keselamatan dan kesehatan. Maka dengan hasil tersebut, dapat disimpulkan bahwa kinerja aset di Pasar Ciwidey kurang baik.
\end{abstract}

Kata Kunci : manajemen aset, manajemen fasilitas, kinerja aset, pasar rakyat.

\section{PENDAHULUAN}

Keberadaan pasar rakyat membantu masyarakat dan pemerintah dalam kegiatan jual beli dan distribusi barang. Pasar rakyat membantu pemerintah dalam mensejahterakan kehidupan, baik itu pedagang, pembeli, dan pihak-pihak terkait yang menggantungkan kehidupannya di pasar tradisional. Pasar rakyat juga berperan penting dalam distribusi lokal, menyeimbangkan penawaran dan permintaan barang masyarakat. Menurut Suartha (2016), pasar adalah suatu tempat pertemuan antara penjual dan pembeli untuk melakukan transaksi. Adapun saat ini masyarakat mengenal dua jenis pasar yaitu pasar tradisional dan pasar modern. Dalam UU No. 7 Tahun 2014 tentang Perdagangan dijelaskan bahwa istilah pasar tradisional berubah menjadi pasar rakyat. Pasar Rakyat adalah tempat usaha yang di tata, di bangun, dan di kelola oleh Pemerintah, Pemerintah Daerah, Swasta, Badan Usaha Milik Negara dan/atau Badan Usaha Milik Daerah, dapat berupa toko, kios, los, dan tenda yang dimiliki/dikelola oleh pedagang kecil dan menengah, swadaya masyarakat, atau koperasi serta usaha mikro, kecil, dan menengah dengan proses jual beli barang melalui tawar-menawar.

Salah satu pasar yang dikelola oleh Pemerintah Kabupaten Bandung melalui Dinas Perindustrian dan Perdagangan adalah Pasar Ciwidey. Sebagai salah satu fasilitas layanan publik yang banyak dikunjungi, pasar seharusnya memiliki fasilitas yang memadai dalam menunjang kebutuhan aktivitas penjual dan pembeli. Fasilitas yang baik akan memberikan kenyamanan dan kelancaran dalam operasional pasar. Tanpa adanya fasilitas yang baik, 
kegiatan operasional pasar akan terganggu. Namun, Pasar Ciwidey termasuk kedalam pasar yang memiliki permasalahan, diantaranya perlu dilakukan pengelolaan pasar yang optimal, menyediakan fasilitas pasar yang belum tersedia dan memperbaiki serta membangun semua infrastruktur pasar (Wir, 2020). Berdasarkan hasil observasi, diketahui bahwa akses jalan di sekitar lingkungan pasar Ciwidey belum digunakan dengan optimal. Sebagian badan jalan dimanfaatkan oleh beberapa pedagang untuk menjajakan dagangannya, sedangkan jalan tersebut juga dapat dimanfaatkan sebagai akses kendaraan pemadam kebakaran atau mitigasi bencana. Disamping itu, di area pasar Ciwidey juga tidak terdapat pos keamanan, kamera pengawas ataupun titik kumpul (assembly point) untuk kondisi darurat.

Kinerja asset Pasar Ciwidey ini diukur menggunakan Standar Nasional Indonesia (SNI) untuk mengetahui tingkat kesesuaian di pasar tersebut. Berdasarkan hasil pengamatan, jika ditinjau dari SNI 8152:2015, terdapat beberapa hal yang tidak sesuai sehingga kinerja pasar tersebut tidak optimal seperti belum adanya ruang terbuka hijau, ruang menyusui dan pos kesehatan. Disamping itu, pasar Ciwidey dapat dikatakan tidak cukup ramah bagi kaum difable (tuna daksa dan tuna netra), hampir seluruh area pasar. Hal ini dilihat dari kondisi koridor yang tidak memiliki anak tangga, tidak rata di beberapa bagian lantai dan terdapat lubang, adanya saluran drainase yang membelah koridor yang hanya ditutup papan dan pada beberapa bagian dipenuhi oleh barang dagangan.

Kondisi tersebut diatas merupakan kondisi yang memprihatinkan karena pasar bukan hanya sekedar bangunan saja tapi juga merupakan sebuah kekayaan bagi daerah. Disamping itu, sistem manajemen yang buruk dapat memberikan kerugian yang lebih besar. Sebagai contoh, jika suatu hari terdapat bencana tak terduga misalnya seperti kebakaran maka kerugian yang didapat tidak hanya terkait bangunan beserta segala isinya namun juga dampak sosial ekonomi pada masyarakat (Saat \& Soemitro 2009). Tindakan utama untuk mengurangi nilai resiko yaitu dengan tindakan pencegahan. Selain itu, angka keamanan untuk infrastruktur dan fasilitas publik harus lebih tinggi dari pada infrastruktur dan fasilitas pribadi (Soemitro \& Suprayitno, 2019). Maka dari itu, untuk mengoptimalkan potensi yang dimiliki dan mencegah terjadinya bencana di pasar, perlu dilakukan penelitian untuk menilai kondisi eksisting pasar tersebut (Saat \& Soemitro 2009).

Berdasarkan identifikasi permasalahan yang telah diuraikan, penelitian ini bertujuan untuk menganalisis kondisi pasar Ciwidey secara komprehensif dengan melakukan evaluasi kinerja pasar rakyat Ciwidey berdasarkan SNI 8152:2015 Penelitian ini mencoba untuk menjawab bagaimana kinerja pasar rakyat Ciwidey dari beberapa aspek, seperti aspek fisik, alokasi tugas dan perlengkapan, lingkungan, dan kesehatan dan keselamatan. Pembahasan dalam penelitian ini terbagi menjadi lima bagian. Bagian pertama adalah pendahuluan yang memaparkan latar belakang dan tujuan dari penelitian. Bagian kedua adalah studi pustaka yang mendukung dalam penelitian. Bagian ketiga yang merupakan pengumpulan data yang dibutuhkan untuk penelitian. Bagian keempat merupakan analisis dari penelitian. Terakhir adalah penutup yang memaparkan kesimpulan hasil studi dari penelitian.

\section{STUDI PUSTAKA}

\section{Manajemen Aset}

Aset fisik yang berada didalam suatu kawasan merupakan bagian penting sebagai penunjang aktivitas dari orang-orang yang ada di kawasan tersebut. Bentuk kegagalan dan kerusakan dari sebuah aset fisik dapat berakibat signifikan dan fatal, sehingga perlu adanya manajemen yang baik terhadap aset fisik. Di samping itu, setiap orang yang bekerja dan beraktivitas di suatu tempat, memiliki hak untuk selalu berada dalam kondisi aman dan nyaman sehingga memberikan kelancaran bagi segala aktivitas yang dilakukan, tanpa merasakan 
ancaman keselamatan yang diakibatkan oleh kurang efektifnya manajemen aset di tempat tersebut (Hastings, 2010).

Menurut Hastings (2010) manajemen aset merupakan serangkaian kegiatan untuk mengidentifikasi kebutuhan aset fasilitas, mengidentifikasi kebutuhan dana, memperoleh aset, menyediakan sistem dukungan logistik dan pemeliharaan untuk aset, menghapus atau memperbaharui aset secara efektif dan efisien sehingga dapat memenuhi tujuan. Manajemen aset dibutuhkan untuk pengambilan keputusan yang tepat agar aset bisa lebih bermanfaat. Manajemen aset ditentukan oleh berbagai dimensi dan sudut pandang. Aset yang dikelola secara efektif dan efisien dapat mencapai tujuan yang diharapkan perusahaan. Manajemen aset tidak sekedar pengelolaan dan pencatatan daftar aset yang dimiliki. Optimalisasi aset harus dilakukan untuk mencegah kerugian yang ditanggung oleh perusahaan.

Adapun tujuan manajemen aset adalah untuk mengoptimalkan potensi penyediaan layanan dari aset dan untuk meminimalisir risiko dan biaya terkait, serta untuk memastikan peningkatan yang positif selama siklus hidup aset (Hastings, 2010). Pada prinsipnya, aset memiliki siklus hidup yang memberikan informasi mengenai keadaan aset semenjak aset tersebut dioperasikan. Menurut Campbell et al (2016) siklus hidup aset tersebut meliputi pembuatan strategi, pembuatan rencana, evaluasi kinerja, pembuatan prosedur, pengoperasian aset, pemeliharaan, inovasi aset, dan penghapusan aset. Campbell et al (2016) menekankan bahwa mengerti dan memahami konsep siklus hidup aset merupakan hal yang penting untuk mengetahui timbal balik dari kinerja aset. Dalam proses pengoperasian aset, ada masa dimana aset tersebut mengalami penurunan kinerja. Untuk memperpanjang umur hidup aset, pengelola aset harus bekerja keras melakukan berbagai strategi agar aset dapat bertahan lebih lama.

\section{Kinerja Aset}

Pengukuran kinerja sangat penting dilakukan karena merupakan faktor kunci dalam mengembangkan suatu aset dengan kebijakan yang lebih baik atas semua sumber daya yang ada di dalamnya. Menurut Abdullah (2014) kinerja adalah prestasi kerja yang merupakan hasil implementasi rencana kerja yang dibuat institusi dan dilaksanakan pemimpin untuk mengetahui kinerja kerja yang dihasilkan itu baik atau kurang baik dilakukan oleh pemerintah maupun perusahaan. Sedangkan menurut Agung (2011) kinerja adalah gambaran mengenai tingkat pencapaian pelaksanaan suatu kegiatan program atau kebijakan dalam mewujudkan sasaran, tujuan, visi dan misi organisasi yang terdapat dalam strategic planning suatu organisasi.

Patacas et al (2015) mengemukakan bahwa pengukuran kinerja aset dapat didasarkan pada beberapa aspek seperti kondisi fisik, alokasi tugas dan peralatan, lingkungan, keselamatan dan kesehatan. Patacas et al (2015) juga mengemukakan bahwa kegiatan pengukuran kinerja aset dapat memberikan informasi mengenai aspek mana saja yang menjadi sebab penurunan performa aset. Hal ini untuk memastikan kinerja dari setiap aspek, dapat juga untuk menilai kriteria keberhasilan dari suatu hasil dampak baik dan buruknya yang dapat diimplementasikan.

\section{Pasar Rakyat}

Prastiawan \& Isbandono (2018) berpendapat bahwa pasar rakyat adalah salah satu pusat budaya di Indonesia, di mana di dalamnya diwujudkan ekspresi perilaku dan nilai yang melekat dalam masyarakat yang terwujud di dalamnya. Sedangkan Lee (2017) menjelaskan bahwa pasar rakyat adalah area perbelanjaan padat produk pertanian dan kelautan, pengepakan daging, pakaian, dan barang grosir dan eceran lainnya. Lee (2017) lebih jauh menjelaskan umumnya pasar rakyat biasanya terletak di pusat hub transportasi, di mana ada penduduk setempat, dan di mana ada kegiatan budaya di kota-kota. Namun, distrik tradisional ini tidak memiliki fasilitas dan tempat parkir, dan tidak peka terhadap perubahan permintaan konsumen.

Bila kita mengacu pada peraturan pemerintah, dalam UU No. 7 Tahun 2014, menjelaskan bahwa pasar adalah lembaga ekonomi tempat bertemunya pembeli dan penjual, baik secara 
langsung maupun tidak langsung, untuk melakukan transaksi perdagangan. Adapun pasar rakyat adalah tempat usaha yang di tata, di bangun, dan di kelola oleh Pemerintah, Pemerintah Daerah, Swasta, Badan Usaha Milik Negara, dan/atau Badan Usaha Milik Daerah dapat berupa toko, kios, los, dan tenda yang dimiliki/dikelola oleh pedagang kecil dan menengah, swadaya masyarakat, atau koperasi serta usaha mikro, kecil, dan menengah dengan proses jual beli barang melalui tawar-menawar.

\section{METODA PENELITIAN}

Penelitian ini menggunakan metode kualitatif. Metode kualitatif digunakan untuk menjelaskan data-data pada kategori fisik, fungsional dan dasar survei. Indrawati (2015) mengemukakan bahwa metode penelitian kualitatif adalah metode penelitian yang melibatkan analisis data berupa deskripsi dan data tersebut tidak secara langsung dapat dikuantifikasikan. Selanjutnya, Indrawati (2015) juga mengatakan jenis penelitian ini berupaya untuk mentransformasikan objek penelitian ke dalam bentuk yang dapat dipresentasikan, seperti catatan lapangan, hasil interview, percakapan, foto-foto, rekaman, dan memo.

Variabel penelitian ditetapkan sesuai dengan ketentuan di SNI 8152-2015. Empat variable diambil disini, yaitu kondisi fisik, penugasan \& peralatan, lingkungan, keselamatan \& kesehatan. Data diambil dari pengamatan langsung dan penilaian yang didasarkan pada jawaban responden.

Menurut Sugiyono (2014), teknik pengumpulan data dapat dilakukan dengan kuisioner (angket), observasi (pengamatan), dan gabungan. Dalam penelitian ini penulis melakukan teknik pengumpulan data gabungan untuk memudahkan pengambilan data kebutuhan penelitian agar lebih detail dan valid. Dalam pengumpulan data, penulis banyak melakukan observasi dan dokumentasi serta wawancara kepada pihak pengelola pasar dan juga ke Dinas Perindustrian dan Perdagangan Kabupaten Bandung. Indrawati (2015) mengemukakan bahwa teknik pengumpulan data merupakan langkah yang paling strategis dalam penelitian, karena tujuan utama dari penelitian adalah mendapatkan data. Tanpa mengetahui teknik pengumpulan data, maka peneliti tidak akan mendapatkan data yang memenuhi standar data yang ditetapkan. Pengumpulan data dapat dilakukan dalam berbagai setting, berbagai sumber, dan berbagai cara. Di lihat dari sumber datanya, maka pengumpulan data dapat menggunakan sumber primer dan sumber sekunder. Teknik pengumpulan data dalam penelitian ini dilakukan dengan observasi, wawancara, dan studi dokumentasi.

Sugiyono (2014) mengemukakan bahwa analisis data adalah proses mencari dan menyusun secara sistematis data yang diperoleh dari hasil wawancara, catatan lapangan, dan dokumentasi, dengan cara mengorganisasikan data ke dalam kategori, menjabarkan ke dalam unit-unit, melakukan sintesa, menyusun ke dalam pola, memilih nama yang penting dan yang akan dipelajari, dan membuat kesimpulan sehingga mudah dipahami oleh diri sendiri maupun orang lain. Analisis data dilakukan untuk mengolah data menjadi informasi sehingga data akan menjadi mudah dipahami dan bermanfaat untuk menjawab masalah-masalah yang berkaitan dengan kegiatan penelitian. Data yang akan dianalisis merupakan data hasil pendekatan survei penelitian dari penelitian lapangan dan penelitian kepustakaan, kemudian dilakukan analisa untuk menarik kesimpulan. Penelitian ini menggunakan data kualitatif untuk mendapatkan sumber informasi yang valid agar dapat menjawab semua kebutuhan yang diperlukan dari data mengenai Pasar Ciwidey. Selain itu, data yang diperlukan banyak diberikan secara dokumentasi agar dapat menyesuaikan dengan hal yang terjadi dilapangan untuk data yang didapat. 
(e)ISSN 2615-1847 (p)ISSN 2615-1839

Jurnal Manajemen Aset Infrastruktur \& Fasilitas - Vol.5, No.1, Januari 2021

\section{ANALISIS PENELITIAN}

\section{Gambaran Umum Pasar Rakyat Ciwidey}

Pasar Ciwidey berada di Kampung Cibeureum Neglasari RT03/RW03 Desa Ciwidey, Kecamatan Ciwidey, Kabupaten Bandung, Jawa Barat. Berdiri sejak tahun 1997 dan dikelola UPTD sejak tahun 2002. Lokasinya sangat strategis karena berada di samping Terminal Ciwidey yang menyediakan beberapa angkutan yang menghubungkan ke Kota Soreang, Kota Bandung, dan sekitarnya. Pengelolaan pasar ini berada di bawah Bidang Sarana Distribusi Perdagangan, Dinas Perindustrian dan Perdagangan Kabupaten Bandung. Pasar Ciwidey melayani 3 Kecamatan yang ada di sekitarnya yaitu Kecamatan Ciwidey, Kecamatan Pasir Jambu, Kecamatan Rancabali, dan Sebagian dari Kabupaten Cianjur dan Bandung Barat. Pasar Ciwidey memiliki luas lahan sekitar $20.931 \mathrm{~m} 2$ dan luas bangunan sekitar $8.292 \mathrm{~m} 2$. Bangunan pasar Ciwidey ini hanya satu lantai, yang digunakan oleh beberapa macam pedagang, yaitu :

1. Kios sebanyak 710 pedagang, dilihat dari Surat Tanda Pemakaian Kios (STPK) yang dikeluarkan

2. Lapak sebanyak 294 pedagang, dilihat dari Surat Tanda Pemakaian Lapak (STPL) yang dikeluarkan

3. Pedagang lapangan sebanyak 374 pedagang

4. Pedagang Kaki Lima (PKL) sebanyak 72 pedagang.

\section{Evaluasi Kondisi Fisik}

Evaluasi kinerja pasar yang digunakan yaitu lokasi, kondisi bangunan, limbah, kesehatan dan keselamatan, indoor environmental quality, akses disabilitas, dan keamanan. Penilaian ini disesuaikan dengan Standar Nasional Indonesia Tahun 2015 untuk mengetahui kondisi fisik pasar.

\section{Kesesuaian Lokasi dengan Rencana Tata Ruang Wilayah}

Gambar 1 merupakan Rencana Tata Ruang dan Wilayah Kabupaten Bandung Tahun 2016-2036. Pasar Ciwidey berada di Kecamatan Ciwidey yang ditandai dengan warna cokelat muda, dimana warna tersebut menunjukkan wilayah kawasan pasar/pertokoan di Kecamatan Ciwidey untuk area pertanian yang ditunjang dengan sarana dan prasarana transportasi yang memadai dan mudah diakses. Keberadaan Pasar Ciwidey sudah tepat sesuai dengan Rencana Tata Ruang dan Wilayah Kabupaten Bandung Tahun 2016-2036 sebagai sarana perdagangan.

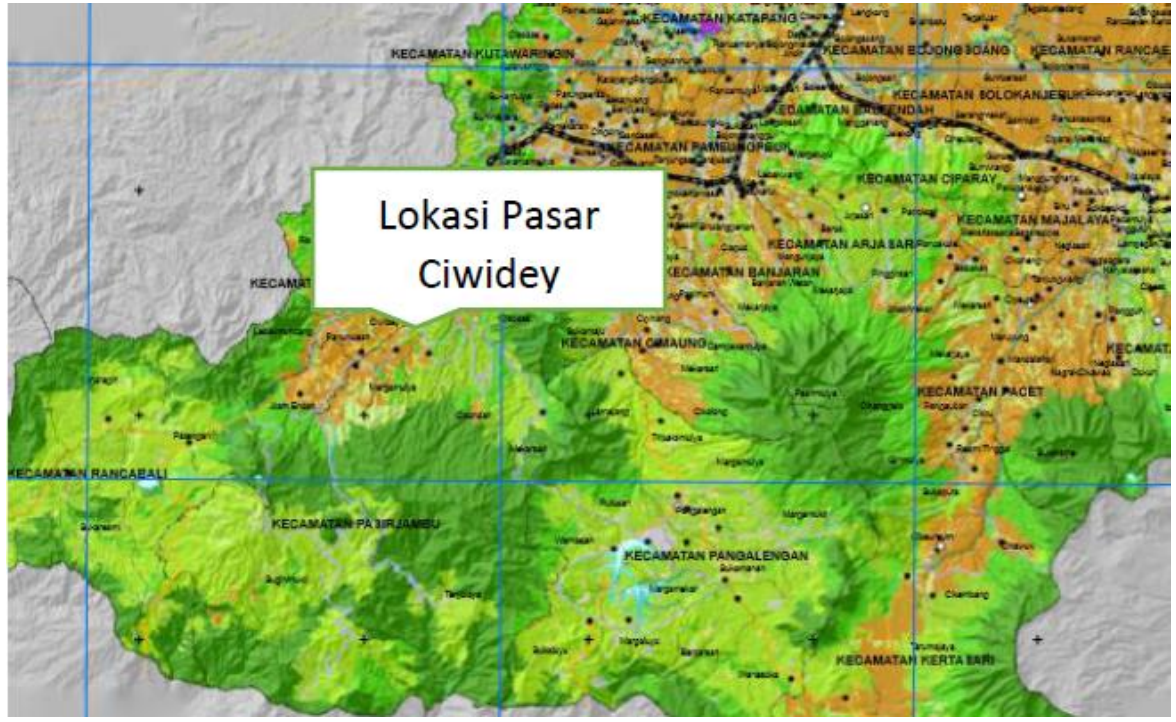

Sumber : Dinas Perindustrian dan Perdagangan Kabupaten Bandung, 2019

Gambar 1. Lokasi Pasar Ciwidey 


\section{Dokumen Kepemilikan}

Berdasarkan hasil wawancara dengan Dinas Perdagangan dan Perindustrian Kabupaten Bandung, Pasar Ciwidey Kabupaten Bandung merupakan aset atau barang milik Pemerintah Kabupaten Bandung yang dapat dipertanggungjawabkan dari segi aspek legal dengan kepemilikan dokumen yang sah.

\section{Bangunan Pasar Ciwidey}

Bangunan pasar harus sesuai dengan persyaratan teknis pasar yang terdiri dari 21 aspek, akan tetapi Pasar Ciwidey belum memenuhi semua hal tersebut. Kriteria bangunan yang belum dapat dipenuhi oleh Pasar Ciwidey ditunjukkan pada Tabel 1.

Tabel 1. Bangunan Pasar Ciwidey

\begin{tabular}{|c|c|c|c|}
\hline No. & Kriteria & Standar Ideal & $\begin{array}{c}\text { Kondisi } \\
\text { Pasar } \\
\text { (existing) } \\
\end{array}$ \\
\hline 1. & Jenis ruang dagang & Kios dan Los & $*$ \\
\hline 2. & Ukuran: luas ruang dagang & Minimal $2 \mathrm{~m} 2$ & * \\
\hline 3. & Jumlah Pos Ukur Ulang & Minimal $2 \mathrm{~m} 2$ & * \\
\hline 4. & Zonasi & $\begin{array}{l}\text { a. Pangan basah } \\
\text { b. Pangan kering } \\
\text { c. Siap saji } \\
\text { d. Non pangan } \\
\text { e. Tempat pemotongan unggas hidup }\end{array}$ & $* *$ \\
\hline 5. & Papan petunjuk zonasi & Ada & $* *$ \\
\hline 6. & Atap & Dalam kondisi baik dan aman & $* *$ \\
\hline 7. & Lantai & Dalam kondisi baik dan aman & $* *$ \\
\hline 8. & Dinding & Dalam kondisi baik dan aman & $* *$ \\
\hline 9. & Area parker & Proporsional dengan luas lahan pasar & $* *$ \\
\hline 10. & Area bongkar muat barang & Tersedia khusus & $* *$ \\
\hline 11. & $\begin{array}{l}\text { Akses untuk masuk dan keluar } \\
\text { kendaraan }\end{array}$ & Terpisah & $*$ \\
\hline 12. & Lebar koridor/gangway & Minimal $1,8 \mathrm{~m}$ & $* *$ \\
\hline 13. & Kantor pengelola & Di dalam lokasi pasar & $*$ \\
\hline 14 & $\begin{array}{l}\text { Lokasi toilet dan kamar mandi } \\
\text { (terpisah antara pria dan } \\
\text { wanita) }\end{array}$ & $\begin{array}{l}\text { Minimal } 4 \text { toilet pria dan } 4 \text { toilet } \\
\text { wanita }\end{array}$ & $* *$ \\
\hline 15. & Jumlah toilet pada suatu lokasi & $\begin{array}{l}\text { Minimal } 4 \text { toilet pria dan } 4 \text { toilet } \\
\text { wanita }\end{array}$ & $* *$ \\
\hline 16. & Ruang Menyusui & Minimal 2 ruang & $* *$ \\
\hline 17. & Ruang Peribadatan & Minimal 2 ruang & $*$ \\
\hline 18. & Ruang bersama & Ada & $* *$ \\
\hline 19. & Area merokok & Ada & $* *$ \\
\hline 20. & Area penghijauan & Ada & $* *$ \\
\hline 21. & $\begin{array}{l}\text { Tinggi anak tangga (untuk } \\
\text { pasar dengan } 2 \text { lantai) }\end{array}$ & Maksimal $18 \mathrm{~cm}$ & $* * *$ \\
\hline
\end{tabular}

\section{$\underline{\text { Limbah Pasar }}$}

Pada indikator limbah disesuaikan dengan SNI 8152:2015 tentang Pasar Rakyat. Indikator limbah dapat diukur melalui 5 aspek yaitu pengujian limbah cair, pengelolaan sampah berdasarkan 3R (reduce, reuse, dan recyle). Pasar Ciwidey hanya dapat memenuhi dua dari lima 
standar yang diharuskan. Aspek-aspek dari pengelolaan limbah yang belum dipenuhi oleh Pasar Ciwidey ditunjukkan pada Tabel 2.

Tabel 2. Limbah Pasar Ciwidey

\begin{tabular}{cllc}
\hline No. & Kriteria & Standar Ideal & $\begin{array}{c}\text { Kondisi } \\
\text { Pasar } \\
\text { (existing) }\end{array}$ \\
\hline 1. & Pengujian limbah cair & Setiap 6 bulan & $* *$ \\
2. & $\begin{array}{l}\text { Pengelolaan sampah } \\
\text { berdasarkan 3R }\end{array}$ & Ada & $* *$ \\
3. & Ketersediaan tempat sampah & $\begin{array}{l}\text { Setiap } \\
\text { toko/kios/los/jongko/konter/perlantaran }\end{array}$ & $* *$ \\
& & dan setiap fasillitas pasar & $*$ \\
4. & Alat angkut sampah & Ada & $*$ \\
5. & Tempat pembuangan sampah & Ada & \\
& sementara & & $*$ \\
\hline Note: “*” menunjukkan sesuai standar, "**” menunjukkan tidak sesuai standar, “***” menunjukkan tidak tersedia.
\end{tabular}

\section{$\underline{\text { Keamanan }}$}

Kriteria keamanan sesuai dengan SNI 8152:2015 yaitu terdapat pos keamanan dan CCTV minimal berada di 2 lokasi berbeda. Kesesuaian dengan kondisi (existing) di Pasar Ciwidey ditunjukkan pada Tabel 3.

Tabel 3. Keamanan Pasar Ciwidey

\begin{tabular}{clcc}
\hline No. & Kriteria & Standar Ideal & $\begin{array}{c}\text { Kondisi } \\
\text { Pasar } \\
\text { (existing) }\end{array}$ \\
\hline 1. & Pos Keamanan & Ada & $* *$ \\
2. & CCTV & Ada & $* *$ \\
\hline Note: “*” menunjukkan sesuai standar, “**” menunjukkan tidak sesuai standar, “***” menunjukkan tidak tersedia.
\end{tabular}

\section{$\underline{\text { Akses Penyandang Disabilitas }}$}

Pasar Ciwidey merupakan fasilitas publik yang dapat digunakan oleh masyarakat. Menurut SNI 8152:2015 tentang Pasar Rakyat, perlu adanya sarana bagi penyandang disabilitas yaitu akses kursi roda dan jalur khusus agar memudahkan untuk melakukan aktivitas. Akses penyandang disabilitas di Pasar Ciwidey ditunjukkan pada Tabel 4.

Tabel 4. Akses Penyandang Disabilitas Pasar Ciwidey

\begin{tabular}{lllc}
\hline No. & Kriteria & Standar Ideal & $\begin{array}{c}\text { Kondisi } \\
\text { Pasar } \\
\text { (existing) }\end{array}$ \\
\hline 1. & $\begin{array}{l}\text { Sarana bagi penyandang } \\
\text { disabilitas yaitu akses kursi } \\
\text { roda dan jalur khusus agar } \\
\text { memudahkan untuk melakukan } \\
\text { aktivitas. }\end{array}$ & Ada & $* *$ \\
\hline
\end{tabular}

Note: “*” menunjukkan sesuai standar, “**” menunjukkan tidak sesuai standar, “***” menunjukkan tidak tersedia. 


\section{Penugasan dan Peralatan}

Pada indikator ini terdapat 4 aspek yang harus dipenuhi sesuai standar. Kondisi Penugasan dan Perlengkapan di Pasar Ciwidey ditunjukkan pada Tabel 5.

Tabel 5. Penugasan dan Perlengkapan Pasar Ciwidey

\begin{tabular}{cllc}
\hline No. & Kriteria & Standar Ideal & $\begin{array}{c}\text { Kondisi } \\
\text { Pasar } \\
\text { (existing) }\end{array}$ \\
\hline 1. & Sarana telekomunikasi & Sesuai dengan jumlah pegawai & $* *$ \\
2. & Informasi indentitas pedagang & Ada & $*$ \\
3. & Informasi kisaran harga & Ada & $* *$ \\
4. & Informasi zonasi pasar & Ada & $* *$ \\
\hline Note: “*” menunjukkan sesuai standar, "**” & menunjukkan tidak sesuai standar, "***” menunjukkan tidak tersedia.
\end{tabular}

\section{Aspek Lingkungan}

Menurut SNI 8152:2015, ada dua aspek lingkungan yang harus dipenuhi pasar, yaitu aspek pencahayaan dan sirkulasi udara. Kondisi aspek lingkungan di Pasar Ciwidey ditunjukkan pada Tabel 6 .

Tabel 6. Asepk Lingkungan Pasar Ciwidey

\begin{tabular}{clcc}
\hline No. & Kriteria & Standar Ideal & $\begin{array}{c}\text { Kondisi } \\
\text { Pasar } \\
\text { (existing) }\end{array}$ \\
\hline 1. & Pencahayaan di setiap koridor & Ada & $* *$ \\
2 & Sirkulasi udara & Ada & $*$ \\
\hline Note: “*” menunjukkan sesuai standar, “**” menunjukkan tidak sesuai standar, "***” menunjukkan tidak tersedia.
\end{tabular}

\section{Keselamatan dan Kesehatan}

Indikator aspek keselamatan dan kesehatan dibagi kedalam 5 aspek. Kondisi aspek keselamatan dan kesehatan di Pasar Ciwidey ditunjukkan pada Tabel 7.

Tabel 7. Keselamatan dan Kesehatan Pasar Ciwidey

\begin{tabular}{cllc}
\hline No. & Kriteria & Standar Ideal & $\begin{array}{c}\text { Kondisi } \\
\text { Pasar } \\
\text { (existing) }\end{array}$ \\
\hline 1. & Pelayanan pos kesehatan & Ada & $* *$ \\
2. & Ketersediaan tabung pemadam & Ada & $*$ \\
& api & & $*$ \\
3. & Hidran air & Ada & $* *$ \\
4. & Jalur evakuasi & Ada & $* *$ \\
5. & Tempat mencuci tangan & Minimal 4 lokasi & $*$ " \\
\hline Note: "** menunjukkan sesuai standar, "**" menunjukkan tidak sesuai standar, "***" menunjukkan tidak tersedia.
\end{tabular}

\section{KESIMPULAN}

Kondisi fisik di Pasar Ciwidey setelah dilakukan analisis kinerja aset terdapat ketidaksesuaian dengan standar yang telah ditetapkan sehingga perlu dilakukannya perbaikan. Fasilitas yang masih kurang membuat penjual maupun pembeli merasa tidak nyaman. Kebutuhan informasi masih sulit didapatkan karena tidak ada papan informasi yang sesuai dengan standar pasar yang telah ditetapkan, sehingga mengurangi kenyamanan dan tidak memberikan informasi mengenai zonasi dagang. Lokasi tempat pembuangan sementara dengan 
area pasar berada dalam jarak yang cukup dekat, sehingga terciup aroma yang kurang sedap yang membuat aktivitas jual beli tidak sehat. Jarak toilet dengan area pasar cukup jauh dan belum terbagi antara toilet pria dan wanita. Pengguna hidran air yang peruntukkanya untuk kebakaran tidak sesuai dengan kebutuhan dan tidak terdapat jalur evakuasi yang sesuai standar. Pengelola pasar perlu melengkapi kebutuhan fasilitas bagi pedagang dan pembeli juga melakukan perbaikan bangunan seperti di bagian atap dan lantai dengan melakukan rejuvinasi.

\section{DAFTAR PUSTAKA}

Abdullah, M. R. (2014). Manajemen dan Evaluasi Kinerja Karyawan. Aswaja Pressindo. Yogyakarta.

Agung, Rai I Gusti. (2011). Audit Kinerja Pada Sektor Publik. Grafindo. Jakarta.

Campbell, J. D., Jardine, A. K., \& McGlynn, J. (Eds.). (2016). Asset management excellence: optimizing equipment life-cycle decisions. CRC Press. New York.

Hastings, N. A. (2010). Physical asset management (Vol. 2). Springer. London.

Indrawati, P.D. (2015). Metode Penelitian Manajemen dan Bisnis Konvergensi Teknologi Komunikasi dan Informasi. PT Refika Aditama. Bandung.

Lee, S. (2017). "A Study on Traditional Market Decline and Revitalization in Korea-Improving the Iksan Jungang Traditional Market". Journal of Asian Architecture and Building Engineering, 16(3), 455-462.

Patacas, J., Dawood, N., Vukovic, V., \& Kassem, M. (2015). "BIM for facilities management: evaluating BIM standards in asset register creation and service life planning". Journal of Information Technology in Construction, 20 (10), 313-318.

Prastyawan, A., \& Isbandono, P. (2018). "The role of local governments in traditional market revitalization". In Journal of Physics: Conference Series Vol. 953, No.1, January 2018.

Saat \& Soemitro R. A. A. (2009). "Evaluasi Kondisi Pasar Raya Sebagai Aset Daerah Kota Padang Terhadap Bahaya Kebakaran”. Seminar Nasional Aplikasi Teknologi Prasarana Wilayah 2009.

Soemitro, R.A.A. \& Suprayitno, H. (2019). "Pemikiran Awal tentang Prinsip Tindakan Mitigasi Preventif Resiko Bencana Alam bagi Manajemen Aset Infrastruktur dan Fasilitas". Jurnal Manajemen Aset Infrastruktur \& Fasilitas, Vol. 3, Edisi Khusus 1, Maret 2019.

Suartha, N. (2016). Revitalisasi Pasar Tradisional Bali Berbasis Pelanggan: Studi Kasus di Kabupaten Gianyar. PT Raja Grafindo Persada. Depok.

Sugiyono. (2014). Metode Penelitian Kualitatif, kuantitatif dan R\&D. Alfabeta. Bandung.

SNI 8152:2015. Standar Nasional Indonesia 8152:2015 tentang Pasar Rakyat.

UU 07/24. Undang Undang Nomor 7 Tahun 2014 tentang Perdagangan.

Wir, Bung. (2020).'Tidak Hanya Pasar Ciwidey, Pasar Majalaya Pun Bermasalah' (http://soreangonline.com/) (Diakses 02 April 2020). 
(e)ISSN 2615-1847 (p)ISSN 2615-1839

Jurnal Manajemen Aset Infrastruktur \& Fasilitas - Vol.5, No.1, Januari 2021 